\title{
Urinary Tract Infection among Children - A Study at a Tertiary Pediatric Care Hospital in Hyderabad, India
}

\author{
Ganga Bhavani $^{1}$, B. M. Shanker Venkatesh ${ }^{1 *}$ and B. Venkatachalam ${ }^{2}$ \\ ${ }^{1}$ Department of Microbiology Osmania Medical College, Hyderabad, Telangana, India \\ ${ }^{2}$ Department of Pediatrics, Apollo Medical College, Hyderabad, Telangana, India \\ *Corresponding author
}

\section{Keywords \\ Urinary tract infection, Gram negative bacilli, Klebsiella, Antimicrobial susceptibility, Imipenem}

\section{Article Info}

Accepted: 22 May 2018 Available Online: 10 June 2018

\section{A B S T R A C T}

Urinary tract infection (UTI) is considered as the most common bacterial infectious disease seen among the pediatric patients. Pediatric urinary tract infections are associated with high morbidity and long term complications like renal scaring, hypertension and chronic renal failure The epidemiology of UTI during childhood varies by age, gender and other factors (Bickerton and Ducket, 1985). Most commonly bacteria causes of UTI in children are members of Enterobacteriaceae, particularly uropathogenic strains of E. coli and Klebsiella spp. which are the primary causative pathogens of UTI in the different part of the world (Gautam et al., 2013). Susceptibility patterns of the bacterial isolates vary with geographic region and act as a reference for guiding the empirical therapy. The aetiology of paediatric UTI and the antibiotic susceptibility of urinary pathogens in both the community and hospitals have been changing, and drug resistance has become a major problem (Taneja et al., 2010). With this background, the present study was conducted to observe the profile of the paediatric UTI, to find out the bacterial pathogens involved and their antimicrobial susceptibility pattern at a tertiary paediatric care centre in Hyderabad, Telangana. This retrospective study was undertaken for a period of one year in the department of Microbiology, Institute of child health, Niloufer hospital a tertiary care paediatric hospital in Hyderabad Telangana. A total of 262 cases aged between 2 months to 14 years clinically suspected of UTI, were studied over a period of One Year. The rapid diagnostic test using urocolor 10 strips (Standard Diagnostics Inc.) was performed on all the samples of urine and was correlated with conventional culture. Urine cultures were carried out on blood agar, Mac conkey, CLED agar and Hichrome UTI agar plates and the isolates were identified by Gram staining and conventional biochemical methods. Antimicrobial susceptibility testing was performed by disk diffusion method according to the Clinical and Laboratory Standards Institute (CLSI). Of the 262 children with suspected UTI included in this study, 100(38.16\%) were found to be culture positive. Although urine culture is the standard criteria for diagnosis of UTI, it may take as long as 48 hours for culture to be positive. Hence the rapid diagnostic test using urocolor 10 strips (Standard Diagnostics Inc.) was performed on all the samples of urine and was correlated with conventional culture. Of the total 262 cases, 128 cases showed hematuria, 125 showed Leucocyte Esterase and 93 showed Nitrite test positive on the strip. Out of these the cultures were positive in 78 cases of hematuria, 97 cases of Leucocyte Esterase and 89 cases of Nitrite respectively The sensitivity of dipstick taken individually for hematuria, Leucocyte Esterase and Nitrite test were $60.93 \%, 77.6 \%$ and $95.69 \%$ respectively. When all these parameters were taken combined the sensitivity was $78.07 \%$ and when taken for Leucocyte Esterase and Nitrite test was $86.65 \%$. This confirms to the dipstick sensitivity of $85-90 \%$. In our study 87 samples showed growth with a single organism, while the total number of mixed infections were 13 $(11 \%)$ out of which E.Coli + Enterococci were 4, Klebsiella + Enterococci 4, pseudomonas + candida 2 and E.Coli + CONS 3; An analyses of the results of present study reveals that amongst the various etiological agents isolated, Escherichia coli (55\%) was found to be the most predominant organism in paediatric UTI,followed by klebsiella pneumoniae (26\%)) The third in order of frequency was Enterococci which accounted for 10\%. The other organisms isolated include Proteus mirabilis 2\%, Pseudomonas aeriginosa 2\%, Enterobacter 2\%, Citrobacter $1 \%$ The present study reveals that most of the gram negative organism (GNB) were sensitive to Imipenem (95\%), Amino glycosides 75\%, Amoxyclav 60\%, Piperacillin + Tazobactum 70\% and 3rd generation cephalosporins $55 \%$. The most resistant organism was pseudomonas which was sensitive only to Imipenam and piperacillin + Tazobactum. Pediatric urine culture isolates are becoming increasingly resistant to commonly used antibiotics. Finally, we suggest that empirical antibiotic selection should be based on knowledge of the local prevalence of bacterial organisms and antibiotic sensitivities rather than on universal guidelines. 


\section{Introduction}

UTI is one of the most common debilitating infections of childhood. Pediatric urinary infections are associated with high morbidity and long term complications like renal scaring, hypertension and chronic renal failure (Chon et al., 2001). It is estimated that approximately $7 \%$ of children between 2 months to 2 years of age with undifferentiated febrile illness and $8 \%$ of children between 2 19 years of age presenting with possible urinary symptoms suffer from UTI. The reported incidence of UTI is 7\% among girls and $2 \%$ among boys during the first 6 years of life (Edlin et al., 2013). The epidemiology of UTI during childhood varies by age, gender and other factors (Bickerton and Ducket, 1985). The incidence is highest in the first yearr of life for all children (1\%) but decreases substantially among boys after infancy. Under the age of $1 \mathrm{yr}$, the incidence of UTI in boys is higher than in girls; In the first year of life, especially in the first three months, UTI is seen more commonly in boys $(3.7 \%)$ than in girls (2\%). Thereafter, the UTI has been reported to be much more likely in girls $(3 \%)$ than boys (1.1\%) (Grabe et al., 2013). Majority of UTI in children result due to ascending infection, although hematogeneous spread may be more common in the first year of life. Individual differences in susceptibility to UTI may be due to host factors such as production of urethral and cervical $\operatorname{IgA}$ antibodies as well as other factors that influence bacterial adherence to the introitus and the urethral epithelium. (Roberts, 1996; James-Ellison et al., 1997). Children are at risk of developing UTI due to certain anatomic, physiologic factors and Congenital anomalies of the urinary tract among which vesicoureteric reflux (VUR) is the most common, leading to repeated infections and other complications like chronic pyelonephritis and eventual renal scarring which are components of reflux nephropathy, and other congenital anamolies like posterior urethral valve, ureteric duplex, etc., are also well known causes of UTI in children (Aggarwal and Verrier Jones, 1989)

In children most often urinary tract infection (UTI) manifests as fever of unknown origin. The clinical presentation of UTI in infants and young children can vary from occult and undiagnosed fever to gastrointestinal manifestations as well as upper and lower urinary tract symptoms, whereas in older children symptoms referring to the urinary tract may be observed (Grabe et al., 2013). Hence, it is important to diagnose this condition at the appropriate time as it is a preventable cause of renal damage.

UTI is defined by the presence of organisms in the urinary tract, which is usually sterile. In the 1950's Kass studied adult women and established a threshold of $\geq 10^{5} \mathrm{cfu} / \mathrm{ml}$ in a voided specimen as the standard to define positive urine culture. Hobermann et al., noted that high proportion $(65 \%)$ of cultures with colony counts 10,000 to 49,000 grew mixed or Gram positive organisms suggestive of contamination. For boys and girls $10^{4}$ and $10^{5}$ cfu per $\mathrm{ml}$ of bacterial growth of a single type was taken as threshold (significant bacteriuria) respectively (Neelan Taneja et al., 2010)

Bacteria are common causes of UTI in children with Escherichia coli being the most commonly isolated pathogen. The gold standard for diagnosis of UTI is growth of pathogenic bacteria in a urine culture Although urine culture is a gold standard for diagnosis of UTI, results are not available for 24-48 hrs. rapid technique to predict UTI include urine dipstick tests for lucocits sterase and nitrites and various forms of urinalysis including standard microscopy with a haemocytometer and Gram stain of uncentrifuged urine for organisms (Joseph, 2005). 
Susceptibility patterns of the bacterial isolates vary with geographic region and act as a reference for guiding the empirical therapy. The aetiology of paediatric UTI and the antibiotic susceptibility of urinary pathogens in both the community and hospitals have been changing, and drug resistance has become a major problem (Taneja et al., 2010). In recent years, widespread use of antibiotics has been resulted in an increasing incidence of antibiotic resistance among the urinary tract pathogens all over the world. Worldwide, emerging of antibiotic resistance is increasing among the urinary pathogens. (Kahlmeter, 2003; Runehagen and Kahlmeter, 2002) The increase in resistance of microorganisms to antimicrobial agents, especially in hospitalized patients, demands rapid identification of the pathogen. (Ashkenizi et al., 1991; Marray, 1990; Alon et al., 1987) Urinary tract infection (UTI) is the fourth most common reason for prescribing antibiotics, accounting for approximately $8 \%$ of all antibacterial prescriptions [Bickerton and Ducket, 1985]

With this background the present study was undertaken to determine the microbiological profile of UTI to find out the bacterial pathogens involved and their antimicrobial susceptibility pattern by traditional culture methods and also evaluation by rapid tests in early detection of pediatric UTI in children attending a tertiary care center - Institute of child health, Niloufer hospital, Hyderabad.

\section{Materials and Methods}

This cross-sectional study comprimising of 262 clinically suspected cases of UTI from the paediatric medicine and PICU and the paediatric surgical wards was undertaken in the department of Microbiology in collaboration with the departments of Pediatrics, at the institute of child health, Niloufer hospital a tertiary care centre for children in Hyderabad.

\section{Inclusion Criteria}

Children (2m -14years) attending Niloufer hospital suspected to have UTI with symptoms like burning micturition, dysuria, frequency, suprapubic pain, fever with or without chills, haematuria, flank pain

\section{Exclusion criteria}

Neonates below 2 month of age,

Informed written consent were obtained from their guardians/parents. Background information was collected from the guardian regarding the demographic details of the patient, previous incidence of UTI, family history of UTI/VUR, drug intake, previous interventions, and any other complaints.

\section{Sample collection}

The clean-catch mid-stream urine samples collected under strict aseptic conditions from patients were processed

Method of processing

Urine was processed soon after collection in order to minimize the multiplication of any contaminating organisms

The appereance and colour of urine was observed and noted as clear or turbid or blood tinged

Direct wet mount was done for presence of pus cells, apart from pus cells, urine was screened for epithelial cells, RBC, crystals, casts, bacteria, yeast cells which are of diagnostic significance.

Gram Stain of uncentrifuged urine sample was done for the presence of organism, though it is unreliable in detecting UTI when the count of the organism is low yet it is clinically 
significant in pyelonephritis, invasive UTI and for the immediate management.

\section{Dip stick analysis (LN strip)}

Which does microscopic enumeration of neutrophils, reflects pyuria,and is an easy, inexpensive means to provide information as to the nature of infecting organism (bacteria or yeast), a guide to emperic therapy,and a method to estimate bacteriuria was done.

\section{Urine culture}

Urine culture is a gold standard for diagnosis of UTI. culture was done according to the standard microbiological procedures with a calibrated one microlitre loop using the semiquantitative method of plating onto blood agar, Mac conkey, CLED agar and Hichrome UTI agar plates to isolate the uropathogens.

Identification and confirmation of isolates was done by the standard identification method

\section{Identification of Organisms on Hichrome UTI agar}

Colonies on Hichrome UTI agar gives presumptive diagnosis of organisms. It is often added as mixture of two chromogens, the chromogen serves as substrate i.e., cleaved by specific enzymes produced by bacteria. The resulting chromophores colours the colony that can be differentiated on the basis of different colour reactions

Escherichia coli - pink red colour colonies • Klebsiella pneumonia - blue mucoid coloni•Pseudomonas spp - colour less • Staphylococcus aureus - white $\bullet$ Enterococcus faecalis - small bluish green. Mueller-Hinton agar was used for susceptibility testing and Nutrient agar for preservation of organism. The antibiotic sensitivity testing was performed using the Kirby-Bauer method as per the Clinical Laboratory Standards Institute (CLSI)

For gram negative isolates the following discs were used

Amoxycillin [AX] 20 ug, Gentamycin (G)

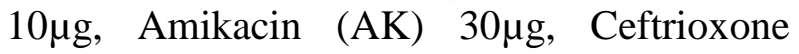
(CTX) $30 \mu \mathrm{g}$, Cefotoxime (CF) $30 \mu \mathrm{g}$, Ceftazidime (CPZ) 10 $\mu$ g, Ciprofloxacin [CIP] $5 \mu \mathrm{g}$, Norfloxacin [NR] 10, Pipercillin + Tazobactum [PT] $100 \mu \mathrm{g} / 10 \mu \mathrm{g}$, Imipenum [IM]10 $\mu \mathrm{g}$

For Gram positive isolates

Amoxycillin [AX] $20 \mathrm{ug}$, Oxacillin[OX\} 1ug, Gentamycin [G] 10ug, Amikacin [AK] 30ug, Amoxyclav [AC] $30 \mathrm{UG}$, Cefotaxime [CA] 30 ug, Ceftrioxone [CTX]30ug, Cotrimoxazole $[\mathrm{CO}] 25$ ug, Ciprofloxacin

\section{Results and Discussion}

Of the 262 children with suspected UTI included in this study, 157 were males and 105 were females. From among the male(157) specimens 62 and from the females (105) specimens, 38 were found to be culture positive thus a total of $100(38.16 \%)$ were culture positive. The age and gender of children from whom the culture positive samples were collected are shown in table 4 Maximum number of cases was seen in age group less than 2 years, where males were 79 and females were 23 and majority of female culture positive cases were in age group 6 to 14 years

The major uropathogens isolated were Escherichia coli(55\%), with majority in female than that of male followed by Klebsiella pneumoniae (26\%). Enterococci spp. (10\%). Proteus sp, Pseudomonas, Enterobacter, $(02 \%)$, Citrobacter $(01 \%)$ were the other bacteria that have been isolated With 
regards to the sensitivity the present study reveals that most sensitive antibiotic was Imipenem (95\%), followed by Amino glycosides 75\%, Amoxyclav 60\%, Piper + Tazo $70 \%$ and 3rd generation cephalosporins $55 \%$.

In this study, the highest resistance rate was to Amoxycillin, followed by Cotrimoxazole

The most antibiotic resistant organism was pseudomonas which was sensitive only to Imipenam and piperacillin + Tazobactum

In vitro sensitivity testing in our study showed many strains of E.Coli were resistant to amoxycillin 90\%, gentamycin $66 \%$, cotrimoxazole $82 \%$ and ciprofloxacin $85 \%$.

Klebsiella spp., the second common organism causing UTI, showed the highest sensitivity to Imipenam $92 \%$ and piperacillin + Tazobactum $70 \%$ and amikacin $76 \%$. and the highest resistance to amoxycillin $88 \%$ and cotrimoxazole $76 \%$

Enterococcus species was sensitive to Vancomycin (90\%) and Aminoglycosides and Amoxiclav (60\%). They were partly sensitive to Amoxicillin (45\%) and floroquinolones $(40 \%)$ and least to cotrimoxal (22\%)

As per our study among 262 urine samples tested males were $157(59.92 \%)$ and females were $107(40.08 \%)$

In our study, out of the total samples. 100 samples(38.16\%)were only culture positive.

Other studies by (Malla et al., 2008) (39.5\%), (Taneja et al., 2010) (28.3\%), (Rai et al., 2008) (28.6\%) and (Sharmin et al., 2009) (46.6\%), showed similar results, while some studies showed lower positive rate than present study (1.39\%), (Rai et al., 2008), (7.3\%) and (Godwin et al., 2010), (Ranjbar et al., 2009) (16.2\%).Such variations might be due to inclusion of only those having complication of renal disease in higher culture cases and lower rate positive culture due to inclusion of all children of certain locality and variation on sample size

UTI is found to be the common problem in children and depends upon the age and sex of the children.

Occurrence of UTI among male children is more than female in first year of life and female after one year of age. Present study shows high rate of UTI among male children as compared to that of female

In the present study, maximum number of cases i.e. 103 cases were seen in age group $<2$ years with culture positivity of $39.21 \%$, followed by 2-5 years age group 88 cases with culture positivity of $36.36 \%$ and 6-14 years age group 72 cases with culture positivity of $38.88 \%$.

Grag (1966) reported in the age group of 0-2 years $(32.79 \%)$ cases, in the age group of 2-5 years $(31.17 \%)$ of cases and in the age group of 5-12 years $(35.48 \%)$ of cases.

Shiela Ethraj et al., (1976) reported (47\%) of cases in the age group of 0-2 years, (24\%) in the age group of $2-5$ years and in the age group of 5-12 years. (29\%) of case. The above studies are almost similar to our study.

In the present study, increase incidence of urinary tract infection in the male patients is due to higher incidence of urinary tract infection associated with vesicle calculus leading to stasis of urine and allowing the micro-organisms to multiply in urine. In the neonatal age group there is male predominance of the condition with $2.2 \%$ of males and $0.3 \%$ of females being affected. 
Table.1 Showing distribution of male \& female cases

\begin{tabular}{|c|c|c|}
\hline Total no. of cases & Males (percent) & Females (percent) \\
\hline 262 & $157(59.92 \%)$ & $105(40.08 \%)$ \\
\hline
\end{tabular}

Table.2 Showing culture positivity among total cases

\begin{tabular}{|c|c|c|}
\hline Total no. of cases & culture positive & percent \\
\hline 262 & 100 & $38.16 \%$ \\
\hline
\end{tabular}

Table.3 Culture positivity among male \&female cases

\begin{tabular}{|c|c|c|c|}
\hline Gender & Total no. of cases & Culture positive & percent \\
\hline Males & 157 & 62 & $39.49 \%$ \\
\hline Females & 105 & 38 & $36.19 \%$ \\
\hline
\end{tabular}

Table.4 Incidence of UTI with regards to Age and Sex

\begin{tabular}{|c|c|c|c|c|c|c|}
\hline \multirow[t]{2}{*}{ Age } & \multicolumn{2}{|c|}{ Sex } & \multicolumn{2}{|c|}{ culture positive } & \multicolumn{2}{|c|}{ Percent } \\
\hline & $\begin{array}{l}\text { Male } \\
(157)\end{array}$ & $\begin{array}{c}\text { female } \\
(105)\end{array}$ & $\begin{array}{r}\text { Male } \\
(62)\end{array}$ & $\begin{array}{c}\text { female } \\
(38)\end{array}$ & Male & female \\
\hline$<2$ years & 79 & 23 & 34 & 06 & $43.03 \%$ & $26.08 \%$ \\
\hline 2-5 years & 50 & 38 & 20 & 12 & $40 \%$ & $31.57 \%$ \\
\hline 6-14 years & 28 & 44 & 08 & 20 & $28.57 \%$ & $45.45 \%$ \\
\hline
\end{tabular}


Table.5 Showing Organism isolated, number and percent

\begin{tabular}{|l|c|c|}
\hline \multicolumn{1}{c|}{ Organism Isolated } & TOTAL STRAINS ISOLATED & PERCENT \\
\hline Escherchia coli & 55 & $55 \%$ \\
\hline Klebsiella pneumonia & 26 & $26 \%$ \\
\hline Enterococci & $\mathbf{1 0}$ & $\mathbf{1 0 \%}$ \\
\hline Proteus & 02 & $02 \%$ \\
\hline Pseudomonas & 02 & $02 \%$ \\
\hline Enterobacter & 02 & $02 \%$ \\
\hline Citrobacter & 01 & $01 \%$ \\
\hline CONS & 01 & $01 \%$ \\
\hline
\end{tabular}

Table.6 Antibiotic sensitivity pattern amoung different organisms

\begin{tabular}{|c|c|c|c|c|c|c|c|c|c|c|c|}
\hline ANTIBIOTIC & $\begin{array}{l}\text { E.coli } \\
{[55]} \\
\mathrm{S} \quad \mathrm{R}\end{array}$ & $\begin{array}{l}\text { Kleb. } \\
{[26]} \\
\text { S R }\end{array}$ & $\begin{array}{l}\text { Proteus } \\
{[2]} \\
\mathrm{S} \quad \mathrm{R}\end{array}$ & $\begin{array}{l}P s e l \\
{[2]} \\
\text { S }\end{array}$ & $\begin{array}{c}\text { monas } \\
\text { R }\end{array}$ & $\begin{array}{l}\text { Ente } \\
{[2]} \\
\mathrm{S}\end{array}$ & $\begin{array}{c}\text { robater } \\
\mathrm{R}\end{array}$ & $\begin{array}{l}\text { Citrobacter } \\
{[1]} \\
\text { S R R }\end{array}$ & $\begin{array}{l}E n \\
{[10} \\
\text { S }\end{array}$ & $\begin{array}{c}\text { coccus } \\
\text { R }\end{array}$ & $\begin{array}{l}\text { CoNS } \\
{[1]} \\
\mathrm{S} \quad \mathrm{R}\end{array}$ \\
\hline Amoxycillin & 991 & 1288 & $0 \quad 100$ & 0 & 100 & 0 & 100 & $0 \quad 100$ & 45 & 55 & 0100 \\
\hline Gentamycin & 3466 & 7030 & $50 \quad 50$ & 50 & 50 & 50 & 50 & $0 \quad 100$ & 58 & 42 & 6040 \\
\hline AmiKacin & 6634 & 7624 & 1000 & 50 & 50 & 100 & 0 & $100 \quad 0$ & 67 & 33 & 6040 \\
\hline Amoxyclav & 6040 & 6040 & $100 \quad 0$ & 0 & 100 & 100 & 0 & $100 \quad 0$ & 56 & 44 & 6040 \\
\hline Norfloxacin & 3763 & 4060 & $100 \quad 0$ & 50 & 50 & 100 & 0 & $100 \quad 0$ & 44 & 56 & 6535 \\
\hline Ciprofloxacin & 1585 & 6238 & $100 \quad 0$ & 50 & 50 & 100 & 0 & $0 \quad 100$ & 34 & 66 & 7030 \\
\hline Cotrimoxazol. & $18 \quad 82$ & 2476 & $0 \quad 100$ & 50 & 50 & & 100 & $0 \quad 100$ & 22 & 78 & 3070 \\
\hline Piper+tazo & 6733 & 7030 & $100 \quad 0$ & 100 & 0 & 100 & 0 & $100 \quad 0$ & --- & & -- \\
\hline Vancomycin & -- & -- & -- & -- & & -- & & -- & 90 & 10 & 8020 \\
\hline Cefataxime & 5248 & 5446 & $50 \quad 50$ & 50 & 50 & 50 & 50 & $0 \quad 100$ & --- & & --- \\
\hline Ceftriaxone & 5644 & 5644 & $50 \quad 50$ & 50 & 50 & 50 & 50 & $100 \quad 0$ & --- & & -- \\
\hline Imipenem & 964 & 9208 & $100 \quad 0$ & 100 & 0 & 100 & 0 & $100 \quad 0$ & $\ldots$ & & $\ldots$ \\
\hline
\end{tabular}


UTI among girls who are more than one year old is more possibly because of the structural anomalies. (Afsharpaiman et al., 2012) Incidence in first 3 months among boys is more. In this study, the frequencies of positive cultures were more for males than for females. Farajnia et al., reported this ratiol:2 (Farajnia et al., 2009) and Farrell et al., reported this ratio 1:4 (Farrell et al., 2003). The cause of this needs more study.

E. coli (55\%) was the commonest bacterial isolates of all positive cases followed by klebsiella spp (26\%), Enterococci (10\%), Proteus (02\%), Pseudomonas (02\%), Enterobacter (02\%), Citrobacter (01\%), CONS (01\%),

The bacterial isolates in the present study are similar to that of studies by Seyed Reza Mirsoleyman et al., (2014) who reported an incidence of $57.7 \%$ of E.coli and $36.2 \%$ of Klebsiella spp, Gautam et al., (2013) reported $40 \%$ of isolatres as E.coli, Rima H. HannaWakim et al., (2015) also reported an incidence of E.coli at 79\%, Palak Gupta et al., (2015) also reported $68.3 \%$ of E.coli and $21.2 \%$ of Klebsiella spp, Tankhiwale et al., (2004), Sharan et al., (2013) also reported similar incidence

E. coli was the principal isolate showing high susceptibility to Imipenem (96\%) followed by Piperacillin + Tazobactum (67\%).

Many strains of E.Coli in our study showed resistance to Amoxicillin 90\%, Gentamycin 66\%, Cotrimoxazole $82 \%$ and Ciprofloxacin $85 \%$.

Kumari et al., (2005) reported Amikacin as the most sensitive followed by Gentamycin. Other studies by Malla et al., (2008) from Pokhara, Das et al., from western part of Nepal showed Amikacin was the most sensitive drug.
Klebsiella species was found to be the causative agent in about $26 \%$ of cases and was highly sensitive to Imipenam (92\%)) and sensitive to Aminoglycosides (75\%), and Amikacin (76\%) cotrimoxazole $(76 \%)$ piperacillin + Tazobactum(70\%) and ciprofloxacin (62\%). and resistant to Amoxycillin (88\%)

Enterococcus species was sensitive to Vancomycin (90\%) and Aminoglycosides and Amoxiclav (60\%). They were partly sensitive to Amoxycillin (45\%) and floroquinolones (40\%) and least to cotrimoxazole (22\%). \% .

The most resistant organism was pseudomonas which was sensitive only to Imipenam and piperacillin + Tazobactum.

Proteus showed $100 \%$ sensitivity to Amikacin, Gentamycin, Ciprofloxacin \& and Norfloxacin. The present study reveals that most of the gram negative organism (GNB) were sensitive to Imipenem (95\%), Amino glycosides $(75 \%$,) Amoxyclav() Piperacillin + Tazo bactum (70\%), and 3rd generation cephalosporins 55 The most resistant drugs were Amoxicillin, followed by Cotrimoxazole. These significantly higher bacterial resistance rates to antibiotics in our country in comparison with other countries seem to be the result of higher rate of antibiotic usage by families even in the absence of a prescription

Seyed Reza Mirsoleymani et al., (2014), reported E. coli as the leading uropathogen but the resistance pattern of this organism to antibiotics was very different, specimens were $52.2 \%$ and $56.2 \%$ resistant to Ceftriaxone and Cefotaxime, respectively, study by Farajnia $e t$ al., (2009) showed resistance rate of $90.7 \%$ to Ampicillin, $51.8 \%$ to Cotrimoxazol, and $26.5 \%$ to Cefalexin, whereas the highest percentages of susceptibility were seen for Amikacin (96.6\%) and Gentamicin (92.9\%). 
Sharifian et al., (2012). reported the highest susceptibility percentage of E.coli to Ceftriaxone (97.8\%) and Cefotaxime (95.2\%) in 2006 in Tehran [Sharmin et al., 2009]. Studies by Palak Gupta et al., (2015) reported both E.coli and Klebsiella were sensitive to nitrofurantoin, amikacin, cefoperazonesulbactam followed by Meropenem. In a study conducted in Khartoum, Ali and Osman (2009) reported that the mean susceptibility of all isolates was too high to Gentamicin (96\%), Ciprofloxacin (94\%), and Ceftriaxone (90\%) whereas the lowest percentages of susceptibility were reported for Amoxicillin clavulanate (19\%) and Ampicillin (14\%). In a study conducted in the US hospitals, resistance among E. coli was highest for Trimethoprim sulfamethoxazole $(24 \%)$ but lower for Nitrofurantoin $(<1 \%)$ and Cephalothin (15\%) (Edlin et al., 2013). This study revealed a high E.coli resistance rate to antibiotics.

Variation in susceptibility percentage is probably because of the pattern of the sensitivity of microorganisms to antibiotics varies over time and between different geographical locations.

UTI is a significant problem in children and it is a major cause of high morbidity and mortality in developing world. UTI varies with age and gender and, therefore, extensive evaluation is required in boys under one year of age with UTI. Enteriobacteriaceae family was found to be the most common pathogen that causes UTI among the children. Pediatric urine culture isolates were becoming increasingly resistant to commonly used antibiotics over the last 10 years, regular monitoring in large scale is required at regular intervals in order to identify the reliable information about the resistance patterns of urinary pathogen. Long term studies on a large sample of children need to be planned to understand the disease process better in terms of the interplay between the host and microbial factors. This study also highlights the better efficacy of Imipenem, Amino glycosides, Amoxyclav Piperacillin + Tazo bactum and third generation cephalosporins to Gram-negative uropathogens.

Finally it is suggested that empirical antibiotic selection should be based on the knowledge of local prevalence of bacteria and their sensitivities rather than the Universal guidelines.

\section{References}

Afsharpaiman, S., F. Bairaghdar, M. Torkaman, Z. Kavehmanesh, S. Amirsalari, M. Moradi et al., "Bacterial pathogens and resistance patterns in children with community-acquired urinary tract infection: across sectional study," Journal of Comprehensive Pediatrics, vol.3, no.1, pp. 16-20, 2012

Aggarwal VK, and Verrier Jones $\mathrm{K}$. Vesicoureteric reflux: screening of first degree relatives. Arch Dis Child. 1989; 64: 1538-41. [PMC free article] [PubMed]

Aliand, E., and A. Osman, "Acute urinary tract infections in children in Khartoum State: pathogens, antimicrobial susceptibility and associated risk factors," Arab Journal of Nephrology and Transplantation, vol.2, no.2, pp. 11-16, 2009.

Alon U, Davidi G, Brant M, Merzbach D. Five year survey of changing patterns of susceptibility of bacterial uropathogens to Trimethoprimsulphamethoxazole and other antimicrobial agents. Antimicrob Agents Chemother 1987; 31: 126-128.

Ashkenizi S, Even-Tov S, Samra Z, Dinari G. Uropathogens of various childhood populations and their antibiotic susceptibility. J Pediatr Infect Dis 1991; 10: 742-746. 
Bickerton MW, and Ducket JW. Urinary tract infection in pediatric patients, American Urological Association, Houston; Texas 1985

Chon CH, Lai FC, Shorthffe LM. Pediatric urinary tract infections. Pediatr Clin North Am 2001; 48: 1447-1459

Edlin, R.S., D.J. Shapiro, A.L. Hersh, and H.L. Copp, “Antibiotic resistance patterns in out patient pediatric urinary tract infections," The Journal of Urology, vol. 190, no.1, pp. 222-227, 2013

Edlin, R.S., D.J. Shapiro, A.L. Hersh, and H.L. Copp, “Antibiotic resistance patterns in outpatient pediatric urinary tract infections," The Journal of Urology, vol.190, no.1, pp. 222-227, 2013

Ethiraj S, Moses LG, Thangadorai C, Somu N, Gopaul S, Ranganathan G et al., A critical study of urinary tract infection among the pediatric age group. Indian Pediatr. 1976; 13(7): 553-5

Farajnia, S., M. Y. Alikhani, R. Ghotaslou, B. Naghili, and A. Nakhlband, "Causative agents and antimicrobial susceptibilities of urinary tract infections in the northwest of Iran," International Journal of Infectious Diseases, vol. 13, no. 2, pp. 140-144, 2009

Farrell, D.J., I. Morrissey, D. de Rubeis, M. Robbins, and D. Felmingham, "A UK multicentre study of the antimicrobial susceptibility of bacterial pathogens causing urinary tract infection," Journal of Infection, vol.46, no.2, pp. 94-100, 2003.

Gautam G, Regmi S, Magar NT, Subedi B, Sharma T, Regmi SM Int J Infect Microbiol 2013; 2(3): 82-86

Gautam G, Regmi S, Magar NT, Subedi B, Sharma T, Regmi SM Occurrence of urinary tract infection among children attending Gandaki Medical College Teaching Hospital and Research Center,
Pokhara, Nepal Int J Infect Microbiol 2013; 2(3): 82-88

Godwin TJ, Gyuse AN, Odey FI, et al., A survey of antimicrobial susceptibility patterns of bacterial isolates from community acquired significant bacteriuria among pre-school children in a municipality in calabar. Int $\mathbf{J}$ Biol Med Res 2010; 1: 172-17

Grabe M, Bjerklund-johansen TE, Botto $\mathrm{H}$, Wullt B, Cek M, Naber KG, et al., editors. Arnhem. The Netherlands: UAE; 2013. European Association of Urology (UAE). Guidelines on urological infections; pp. 42-9.

Grag BK. Urinary tract infection in the childhood. Indian Pediatr. 1966; 3(1): 18.

Hanna-Wakim RH, Ghanem ST, El Helou MW, Khafaja SA, Shaker RA, Hassan SA, Saad RK, Hedari CP, Khinkarly RW, Hajar FM, Bakhash M, El Karah D, Akel IS, Rajab MA, Khoury M and Dbaibo GS (2015) Epidemiology and characteristics of urinary tract infections in children and adolescents. Front. Cell. Infect. Microbiol. 5:45. doi: 10.3389/fcimb.2015.00045

James-Ellison MY, Roberts R, Verrier-Jones K, Williams JD, Topley N. Mucosal immunity in the urinary tract: Changes in $\operatorname{sgA}, \mathrm{FSC}$ and total $\operatorname{IgA}$ with age and urinary tract infection. Clin Nephrol 1997; 48: 69-7

Joseph. J zorc Diagnosis and management of pediatric urinary tract infection- clinical microbiology review Apr. 2005

Kahlmeter G. An international survey of the antimicrobial susceptibility of pathogens from uncomplicated urinary tract infections: the ECO-sens project. J Antimicrob Chemother 2003: 51: 69-76.

Kumari N, Ghimire G, Gharti Magar JK, Mohapatra TM, Rai A. Antibiogram pattern of isolates from UTI cases in 
Eastern part of Nepal. J Nepal Med Coll 2005; 7: 116-118

Malla KK, Sarma MS, Malla T, Thapalial A. Clinical profile bacterial isolates and antibiotic susceptibility patterns in urinary tract infection in childrenhospital bases Study. J Nepal Paediatr Soc 2008; 28: 52-61.

Marray BE. Problems and mechanisms of antimicrobial resistance. Infect Dis Clin North Am 1990; 3: 423-39

Neelan Taneja et al., IJMR 131, Jan 2010; 101-105

Palak Gupta, Jharna Mandal, Sriram Krishnamurthy, Deepak Barathi, and Nandini Pandit Indian J Med Res. 2015 June; 141(6): 850.

Rai GK, Upreti HC, Rai SK, Shah KP, Shrestha RM. Causative agents of urinary tract infections in children and their antibiotic sensitivity pattern: a hospital based study. JNepal Med Coll 2008; 10: 86-90

Rai GK, Upreti HC, Rai SK, Shah KP, Shrestha RM. Causative agents of urinary tract infections in children and their antibiotic sensitivity pattern: a hospital based study. JNepal Med Coll 2008; 10: 86-90

Ranjbar R, Haghi-Ashtian MT, JonaidiJafari $\mathrm{N}$, Abedini M. The prevalence and antimicrobial susceptibility of bacterial uropathogens isolated from pediatric patients. Iranian J Public Health 2009; 38: $134-138$.

Roberts JA. Factors predisposing to urinary tract infections in children. Pediatr Nephrol 1996; 10: 517-522.

Runehagen R, and Kahlmeter G. A 10- year study of the consumption of quinolones, trimethoprim and mecillinam in relation to the development of antimicrobial resistance in a large number of species. (2002) Poster 417. ECCMID, Milan, Italy

Seyed Reza Mirsoleymani, Morteza Salimi, Masoud Shareghi Brojeni, Masoud Ranjbar, andMojtaba Mehtarpoor International Journal of Pediatrics Volume 2014, Article ID 126142, 6 pages

Sharan R, Kumar D, Mukherjee B. Bacteriology and antibiotic resistance pattern in community acquired urinary tract infections. Indian Pediatr. 2013; 50: 707. [PubMed]

Sharifian, M., A. Karimi, S. R. Tabatabaei, and N. Anvaripour, "Microbial sensitivity pattern in urinary tract infections children: a single center experience of 1,177 urine cultures" International Journal of Pediatrics, vol. 2012, Article ID43653, 6pages, 2012.

Sharmin S S, F Alamgir, Khanam F, Saleh AA. Antimicrobial sensitivity pattern of uropathogens in children. Bangladesh Society of Medical Microbiologists. Bangladesh J Med Microbiol 2009

Taneja N, Chatterjee SS, Singh M, Singh S, Sharma M. Paediatric urinary tract infections in a tertiary care centre from north India. Indian J Med Res. 2010; 131: 101-5. [PubMed]

Tankhiwale SS, Jalgaonkar SV, Ahamad S, Hasani U. Evaluation of extended spectrum beta lactamase in urinary isolates. Indian J Med Res. 2004; 120 . 553-6. [PubMed]

\section{How to cite this article:}

Ganga Bhavani, B. M. Shanker Venkatesh and Venkatachalam B. 2018. Urinary Tract Infection among Children - A Study at a Tertiary Pediatric Care Hospital in Hyderabad, India. Int.J.Curr.Microbiol.App.Sci. 7(06): 3068-3079. doi: https://doi.org/10.20546/ijcmas.2018.706.361 